\title{
Effect of Electrolyte Age and Potential Changes on the Morphology of $\mathrm{TiO}_{2}$ Nanotubes
}

\author{
Hanna Sopha $^{a}$, Ludek Hromadko ${ }^{a}$, Katerina Nechvilovab ${ }^{b}$ Jan M. Macak ${ }^{\mathrm{a}, *}$ \\ ${ }^{a}$ Center of Materials and Nanotechnologies, Faculty of Chemical Technology, University of \\ Pardubice, Nam. Cs. Legii 565, 53002 Pardubice, Czech Republic \\ ${ }^{b}$ Institute of Chemistry and Technology of Macromolecular Materials, Faculty of Chemical \\ Technology, University of Pardubice, Studentska 573, 53210 Pardubice, Czech Republic \\ *Corresponding Author: e-mail: jan.macak@upce.cz
}

\begin{abstract}
In the present work we report on the influence of the age of ethylene glycol-based electrolytes on the synthesis of self-organized $\mathrm{TiO}_{2}$ nanotube layers. Electrolytes of different ages, defined by the total duration for anodization, were explored in order to get insight about how the tube structure changes with the electrolyte age. The results show a strong dependence of the electrolyte age upon the nanotube length and diameter - a phenomena surprisingly not discussed in existing literature. When fresh electrolytes are employed, nanotube arrays with a high aspect ratio are received, while in older electrolytes (i.e. already used for anodization) the nanotube arrays exhibit low aspect ratios. This is very important aspect for the reproducible synthesis of the nanotube layers. Moreover, the effect of the potential on the nanotube dimensions was investigated. Linear dependence of the diameter upon the potential was observed. Last, but not least, the influence of a potential change towards the end of the anodization time was studied. By sweeping the potential to $100 \mathrm{~V}$, or to $5 \mathrm{~V}$ and keeping this for one hour after applying a constant potential of $60 \mathrm{~V}$ for 4 hours, nanotubes underwent interesting morphological changes. In particular, when slow sweeping from $60 \mathrm{~V}$ to $5 \mathrm{~V}$ was carried out, small nanotubes grew in the gaps between the initial nanotubes. Interestingly, these nanotubes layers showed lower adhesion to the underlying substrates.
\end{abstract}

\section{Keywords}

Titanium dioxide; Nanotubes; Anodization; Electrolyte age; Adhesion

\section{Introduction}


Since the first reports by Assefpour-Dezfuly in 1984 [1] and by Zwilling et al. in 1999 [2], the formation of $\mathrm{TiO}_{2}$ nanotubes by anodization of titanium has attracted significant attention due to the great application of the nanotubes in various fields, such as dye sensitized solar cells [3-7], sensors [8-12], photocatalysis [13-15], and biomedical applications [16-18]. For the first generation of nanotube arrays HF-containing electrolytes were employed [1,19,20]. However, in such electrolytes the thickness of the nanotube arrays is limited to about $500-$ $600 \mathrm{~nm}$ due to a fast dissolution of $\mathrm{TiO}_{2}$ [20]. To expand the range of applications of the nanotube arrays, a variety of different electrolytes in combination with optimized anodization conditions were applied during the last decade, leading to different lengths and diameters. This included the use of aqueous electrolytes [21,22], glycerol based electrolytes[23,24], and ethylene glycol electrolytes [25] with $\mathrm{NH}_{4} \mathrm{~F}$ instead of HF.

Moreover, great efforts have been made to alter morphologies of $\mathrm{TiO}_{2}$ nanotubes, for example to produce nanotubes with bamboo structure or with double-walls [26-29]. In addition, highly ordered $\mathrm{TiO}_{2}$ nanotube arrays were achieved by removing the nanotubes after the first anodization of the Ti foils, and applying a second (and even third) anodization step [30,31]. By using a lower potential for the second step anodization, lotus-root shaped nanotubes were obtained [32]. Furthermore, double layer titania nanotube arrays were obtained by subsequent anodization steps, in two electrolytes [33]. Nanotube layers with branched nanotubes were grown by applying different temperatures [34], while n-branched titania nanotubes were fabricated by reducing the applied potential with a factor of $1 / \sqrt{ } \mathrm{n}$ [35].

In the meantime, it has been established in the field that ethylene glycol based electrolytes need to be aged before their first use in order to prepare nanotubes with reasonable quality (i.e. without unwanted debris, or oxide porous layers on the top of the nanotube layer) [36]. This means that the electrolyte has to be pre-anodized before the first use for growing nanotubes in order to improve its performance. To the best of our knowledge, however, no systematic study has been reported until now, that would undertake efforts to find the optimal electrolyte age for the anodization of titanium. In addition, no such study on the dependence of the nanotube length and diameter on the electrolyte age was performed until now. Potential reasons for this involve the need for precise design of experiments, strict monitoring of the electrolyte's utilization time and also it might be difficult to precisely evaluate the fluoride and water content changes during the electrolyte use for anodization.

The influence of the anodization potential on the tube diameter and length was shown for early stage electrolytes approximately 10 years ago, for purely aqueous electrolytes [37, 38], 
mixed water:glycerol electrolytes [39], as well as for some ethylene glycol based electrolytes [39-42]. Recently, Loget et al. [40] used bipolar electrochemistry and prepared $\mathrm{TiO}_{2}$ nanotubes on the bipolar electrode. Due to the potential variation over the bipolar electrode, diameter and length of the nanotubes changed over the length of the electrode. Nevertheless, in all of these contributions slightly different electrolytes (i.e. variations in water and $\mathrm{NH}_{4} \mathrm{~F}$ concentration) were employed. And so, these results are difficult for comparison as they originate from differing conditions. Moreover, these studies were mainly focused on higher anodization potentials [41, 42] or on substrates with artificial Ti layers [43]. Therefore, in this work, we examined the influence of the age of ethylene glycol based electrolytes, containing small amounts of water and $\mathrm{NH}_{4} \mathrm{~F}$, on the tube length and diameter. Furthermore, we performed different anodization procedures involving potential changes to higher or lower potentials towards the end of the anodization time, to elucidate the influence of such an unusual step (as compared to common art in the field) on the nanotube dimensions and morphology.

\section{Experimental}

Prior to anodization, the titanium foils (Sigma-Aldrich $0.127 \mathrm{~mm}$ thick, 99,7\% purity) were degreased by sonication in isopropanol and acetone, then rinsed with isopropanol and dried in air. The electrochemical setup consisted of a 2 electrode configuration using a platinum foil as the counter electrode, while the titanium foils (working electrodes) were pressed against an O-ring of the electrochemical cell, leaving $1 \mathrm{~cm}^{2}$ open to the electrolyte. Electrochemical experiments were carried out at room temperature employing a high-voltage potentiostat (PGU-200V, IPS Elektroniklabor GmbH).

As electrolyte, ethylene glycol was used containing 1.5 vol\% deionized water and $88 \mathrm{mM}$ $\mathrm{NH}_{4} \mathrm{~F}$. All electrolytes were prepared from reagent grade chemicals. Before the first use, all electrolytes were aged for 9 hours by anodization of blank Ti substrates at $60 \mathrm{~V}$ under the same conditions as for the main anodization experiments. If not stated otherwise, titanium foils were anodized for 4 hours after sweeping the potential from $0 \mathrm{~V}$ to $60 \mathrm{~V}$ with a sweeping rate of $1 \mathrm{~V} / \mathrm{s}$. After anodization the titanium foils were rinsed and sonicated in isopropanol and dried.

The structure and morphology of the $\mathrm{TiO}_{2}$ nanotubes was characterized by a field-emission electron microscope (FE-SEM JEOL JSM 7500F). Dimensions of the nanotubes were measured and statically evaluated using proprietary Nanomeasure software. For each 
condition used in this work, we calculated average values and standard deviations from at least 3 different locations on 2 samples of each condition with a high number of measurements $(n \geq 100)$.

The pull-off tests for adhesion analyses were carried out using COMTEST®OP3P (COMING Plus). A circular target, diameter $20 \mathrm{~mm}$, was stuck on the sample by a bicomponent adhesive based on methyl methacrylate and di-benzoyl peroxide mixed in ratio 10:1. One kilogram weight was put on each of sample for 17 hours. The measurement parameters were following: increasing the tension to $120 \mathrm{kPa} / \mathrm{s}$; limit force $15 \mathrm{kN}$. The test was made according to ISO 4624. The result of this test was the force needed to pull-off the layer from the substrate.

\section{Results and discussion}

\subsection{Influence of the electrolyte age on the nanotube diameter and length}

Fig. 1 depicts the current density-time plots recorded during the anodization of titanium at 60 $\mathrm{V}$ for 6 hours in ethylene glycol (containing $88 \mathrm{mM} \mathrm{NH}_{4} \mathrm{~F}$ and $1.5 \mathrm{vol} \%$ DI water) as a function of the electrolyte age, expressed by the number of hours for which the electrolyte had been used to anodize titanium at $60 \mathrm{~V}$, after the initial aging. As can be seen, in all cases the current transients show the typical behaviour reported in earlier papers [44,45]. Even though this behaviour was deeply described and verified in previous literature (for review see ref. [28]), we briefly review it also here for the sake of clarity and discussion of our results. At the beginning of the anodization, when the potential is swept to $60 \mathrm{~V}$, the current strongly increased, an oxide layer was spontaneously formed at the surface of the titanium. Once the final potential had been reached, a fast current density decay was recorded. During the following period, where the current density proceeds through its first minimum, small pores started to grow randomly in the oxide layer, and shortly after the current density increased due to an increase of the active area, until a maximum number of pores was formed. This stage corresponded to a maximum in current density. Subsequently, the tubes expanded in length, and the current density slowly decayed towards a steady-state (which is not reached though within 4 hours of anodization used here). However, depending on the electrolyte age two deviations between the plots can be observed: (i) the time lag to reach the maximum is 
longer, and (ii) the current is generally lower the older the electrolyte. Considering the reactions for the anodic nanotube formation of titanium, governed by a competition of the anodic oxide formation and the chemical oxide dissolution [38]:

$\mathrm{Ti}+2 \mathrm{H}_{2} \mathrm{O} \rightarrow \mathrm{TiO}_{2}+4 \mathrm{H}^{+}+4 \mathrm{e}^{-}$

$\mathrm{TiO}_{2}+6 \mathrm{~F}^{-}+4 \mathrm{H}^{+} \rightarrow\left[\mathrm{TiF}_{6}\right]^{2-}+2 \mathrm{H}_{2} \mathrm{O}(2)$

one can see that fluoride ions are consumed during oxidation, leading to lower concentrations in older electrolytes. This results in lower current densities since fewer fluoride ions remain available, and the $\mathrm{pH}$ value and viscosity are changing [46]. Furthermore, more time is needed to reach the maximum in current density. As a result, the growth rate of the tubes was slower and the length of the $\mathrm{TiO}_{2}$ nanotubes strongly decreased when older electrolytes are used at the same anodization time as shown in Fig. 2. For example tubes produced in a fresh electrolyte were $\sim 26 \mu \mathrm{m}$ long while tubes produced in an electrolyte used for almost 50 hours were $\sim 3.5 \mu \mathrm{m}$ long.

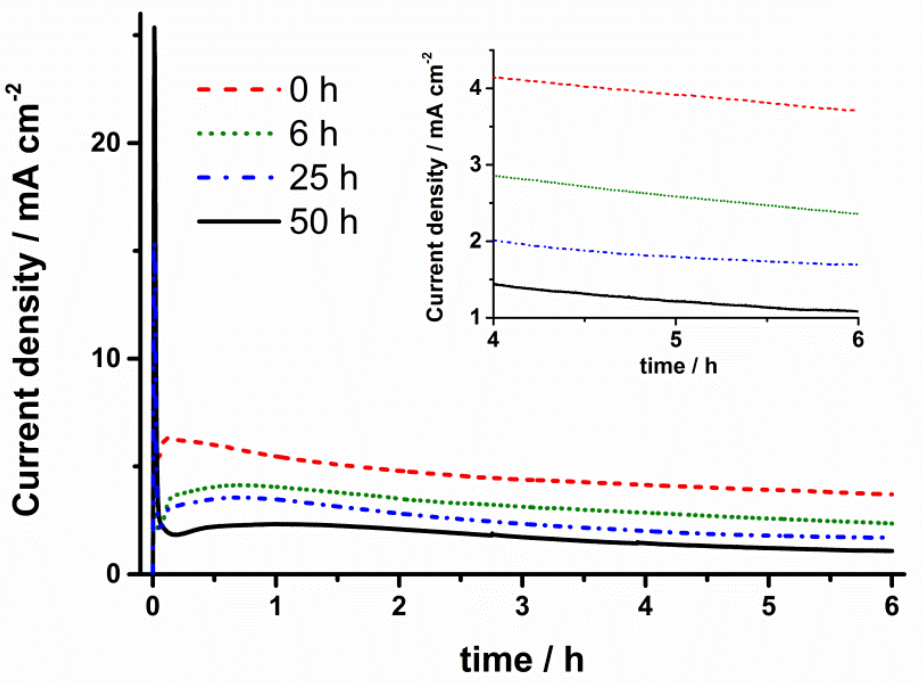

Figure 1. Current-time curves for the anodization of titanium for 6 hours at $60 \mathrm{~V}$ in electrolytes of different ages: $0 \mathrm{~h}$ (dashed line), $6 \mathrm{~h}$ (dotted line), $25 \mathrm{~h}$ (dashed-dotted line) and $50 \mathrm{~h}$ (full line). The inset shows the current-time behaviour during the final two hours of anodization. 
A trend towards larger tube diameters can be observed when older electrolytes are employed as shown in Fig. 3. For example, the diameter obtained in a fresh electrolyte (i.e. aged but had not yet been used for any regular anodization) is $\sim 124 \mathrm{~nm}$, while in the electrolyte which was used for about 50 hours a nanotube diameter of $\sim 154 \mathrm{~nm}$ was observed. This can be explained by an increase in the conductivity and a decrease in the IR drop (potential loss due to the electrical resistance of the electrolyte) [36]. During the anodization process the conductivity of the electrolyte increased, as shown in Table 1, due to the reactions at the electrodes (see equations 1 and 2, as well as reference [36,45]). Subsequently the IR drop becomes lower for older electrolytes and the real potential on the working electrode increased. Since the diameter of the nanotubes strongly depends on the applied potential [38$43,46]$, the diameter of the tubes increased with increasing age of the electrolytes.

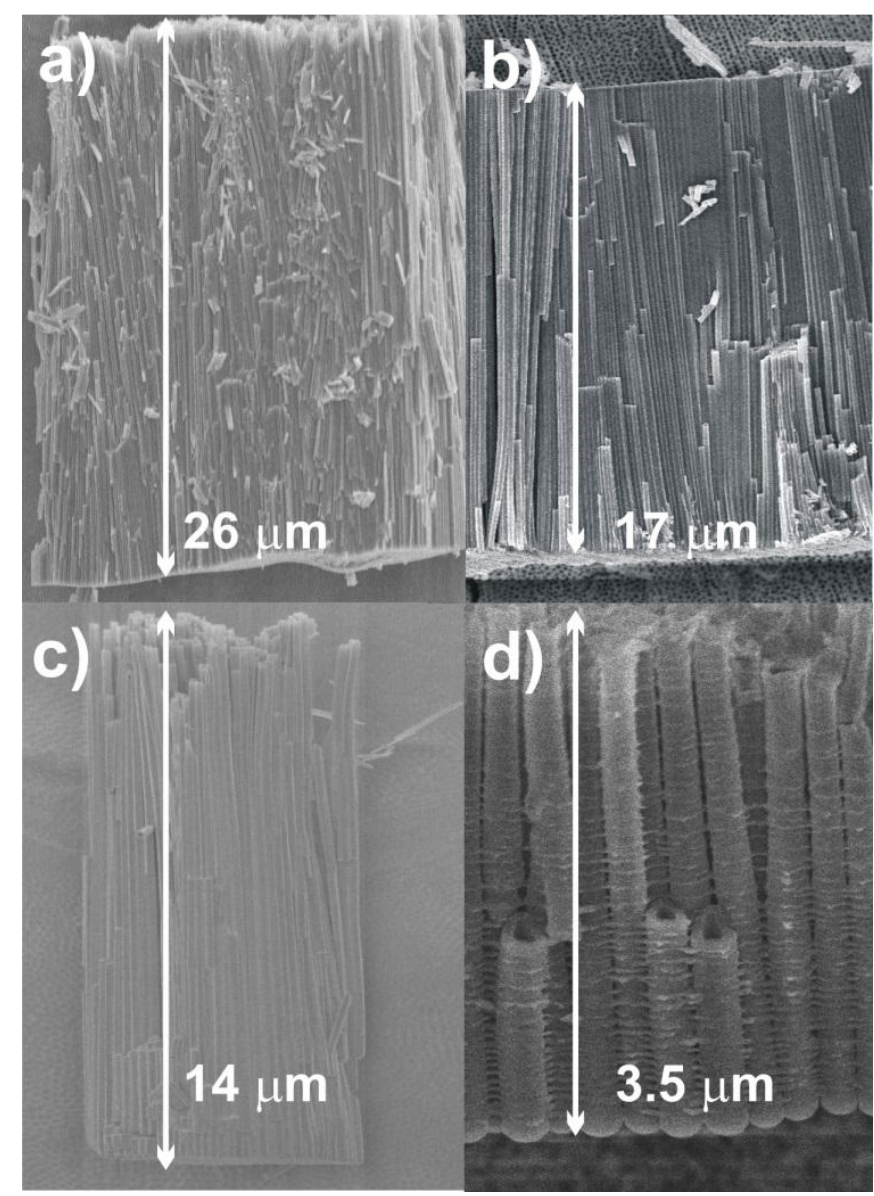

Figure 2. SEM cross-sectional images of the nanotube layers grown for 6 hours at $60 \mathrm{~V}$ in electrolytes of different ages: a) fresh electrolyte, b) 6 h, c) $25 \mathrm{~h}$, and d) $50 \mathrm{~h}$. 


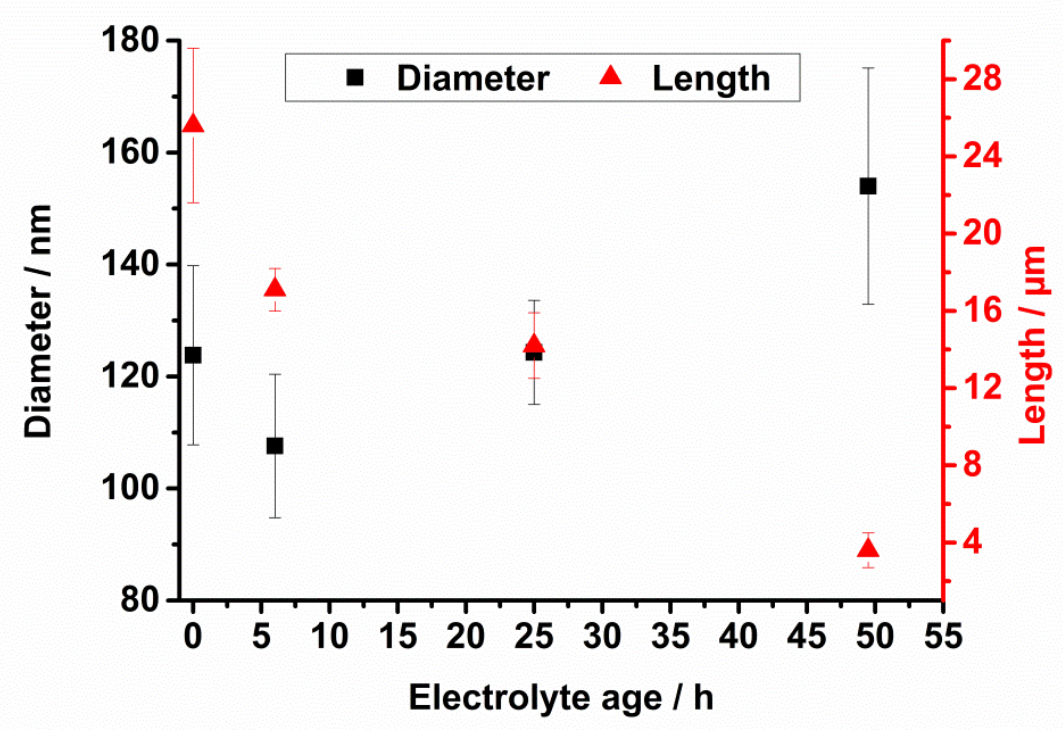

Figure 3. Dependence of the nanotube diameter and the nanotube length on the electrolyte age for 6 hours anodization at $60 \mathrm{~V}$.

Evidently, the electrolyte can actually be used several times without any significant issues of lower quality. However, when it is used for too long a time in total (regardless if for one anodization run only or for a set of anodizations) it becomes weak due to a lack of fluoride ions. As a consequence, the nanotube growth is hindered resulting in a decrease of the aspect ratio, i.e. the aspect ratio is decreasing from $\sim 210$ in a fresh electrolyte to $\sim 23$ in an electrolyte used for 50 hours. The results show that the optimal electrolyte age is in the range of 0 to $\sim 35$ hours after aging for anodizations at $60 \mathrm{~V}$. However, one has to be aware of the gradually decreasing aspect ratio of tubes produced with one electrolyte repetitively.

\begin{tabular}{|l|c|}
\hline Electrolyte age & Conductivity $/ \mu \mathrm{S} \mathrm{cm}^{-1}$ \\
\hline Fresh electrolyte, not aged & $585.3 \pm 1.2$ \\
\hline Fresh electrolyte, aged & $675.7 \pm 1.2$ \\
\hline $\begin{array}{l}\text { Electrolyte used for } 50 \\
\text { hours }\end{array}$ & $801.7 \pm 2.3$ \\
\hline
\end{tabular}

Table 1. Change of the conductivity with the electrolyte age.

3.2. Influence of the anodization potential on the nanotube dimensions 
The dependence of the nanotube diameter and length on the anodization potential for anodization times of 4 hours was investigated as shown in Fig. 4. A range of potentials were used: 20, 40, 60, 80 and 100V. For all potentials applied, electrolytes of exactly the same age were used (i.e. electrolytes directly after aging). As expected, both the tube diameter and the tube length, were increasing linearly when the anodization potential was increased. This demonstrated that nanotubes of controlled length and diameter can be produced by controlling the anodization potential. In fact, under presented conditions nanotubes can be prepared over a wide range of potentials, leading to nanotubes with an inner diameter spanning from approximately 50 to $175 \mathrm{~nm}$. This range was smaller than for mixed water:glycerol electrolytes [39], yet it is very wide.

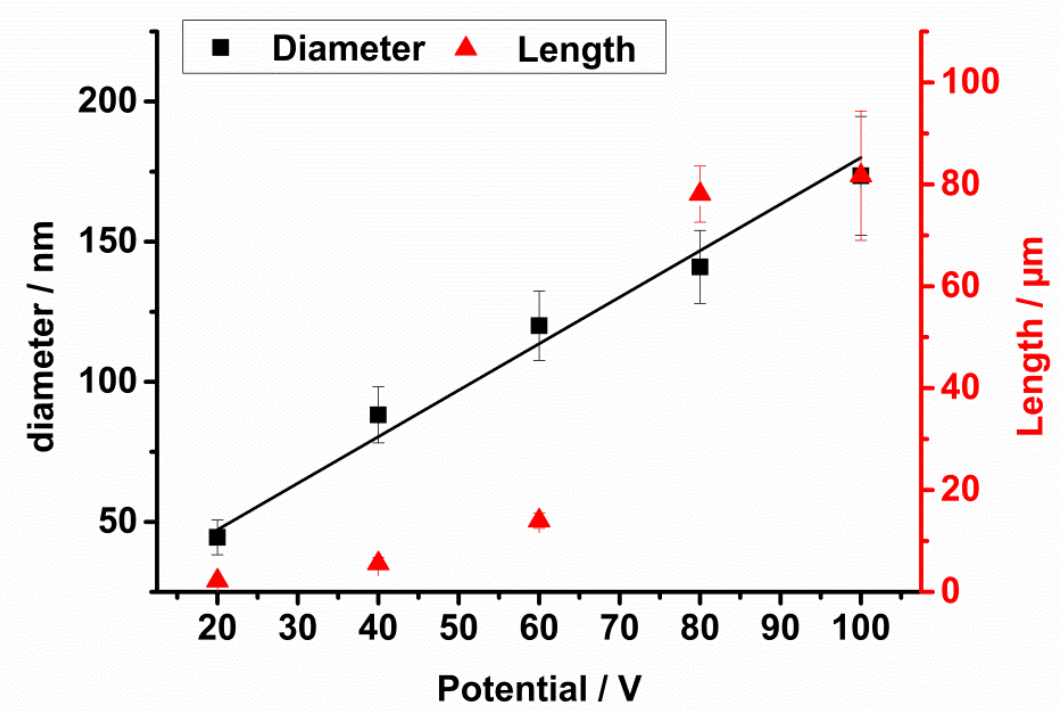

Figure 4. Dependence of the nanotube diameter and length on the anodization potential applied for 4 hours using ethylene glycol electrolyte with $88 \mathrm{mM} \mathrm{NH}_{4} \mathrm{~F}$ and $1.5 \mathrm{vol} \% \mathrm{DI}$ water.

\subsection{Tube morphology after potential changes during anodization}

Fig. 5 depicts the current density-time plots for the anodization of titanium foils when the applied potential was first maintained at $60 \mathrm{~V}$ for 4 hours, and subsequently increased to 100 $\mathrm{V}$, or reduced to $5 \mathrm{~V}$ with sweep rates of $1 \mathrm{~V} / \mathrm{s}$ and $10 \mathrm{mV} / \mathrm{s}$. The second potential $(100 \mathrm{~V}$ and $5 \mathrm{~V}$, respectively) was held for 1 hour. The plots show their typical transients when the potential was held at $60 \mathrm{~V}$ as described in Fig. 1. Then, due to the potential increase in case of a sweep to $100 \mathrm{~V}$ the current density rose to approximately $15 \mathrm{~mA}$. In case of a potential 
decrease to $5 \mathrm{~V}$ the current density decreased to approximately $10 \mu \mathrm{A}$. If the potential was increased rapidly, i.e. with a sweep rate of $1 \mathrm{~V} / \mathrm{s}$, the current density responded with a strong increase as long as the potential was increased. When the potential was then kept at $100 \mathrm{~V}$ the current density continued rising, but with a lower slope. A comparable behaviour can be seen when the sweep rate was as low as $10 \mathrm{mV} / \mathrm{s}$, but the current density increased at a slower rate during the potential sweep. However, after keeping the potential at $100 \mathrm{~V}$ for an hour, the current density was almost identical in both cases.

a)

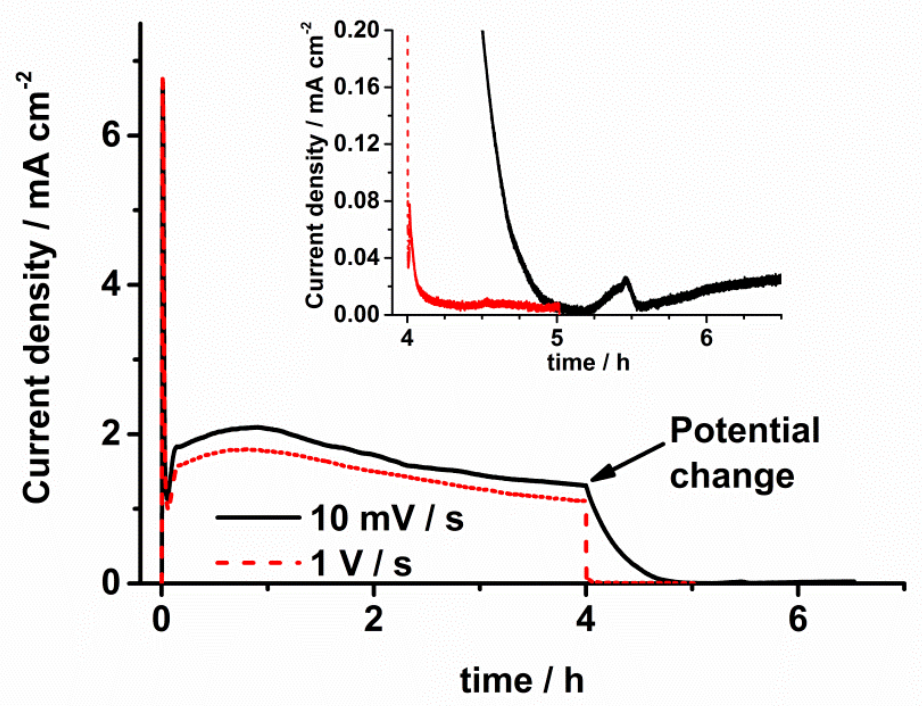

b)

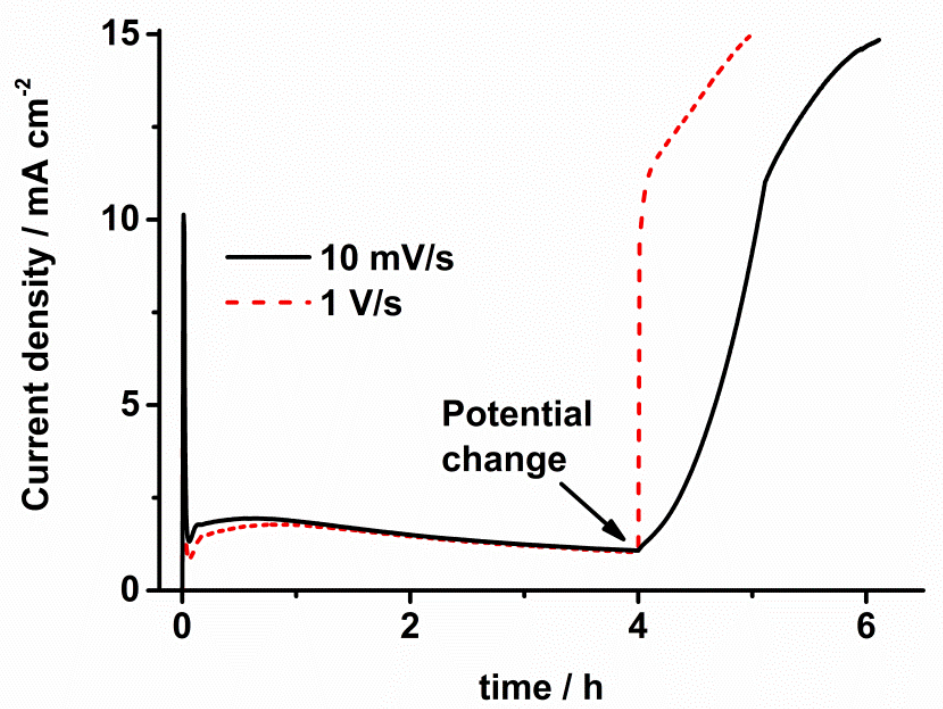

Figure 5. Current-time curves for the application of a constant potential of $60 \mathrm{~V}$ for 4 hours and then a) decreasing the potential to $5 \mathrm{~V}$, or b) increasing the potential to $100 \mathrm{~V}$ with sweep rates of $10 \mathrm{mV} / \mathrm{s}$ (full line), and $1 \mathrm{~V} / \mathrm{s}$ (dashed line), and keeping the new potential for 1 hour. 
When sweeping the potential towards lower potentials the current density decreased. If the potential decays with $1 \mathrm{~V} / \mathrm{s}$, the current decreases to a minimum of about $10 \mu \mathrm{A}$, rises for approximately $50 \mu \mathrm{A}$ when the applied potential amounts to $5 \mathrm{~V}$, and decays again within approximately two minutes. A similar behaviour was observed when a slow sweep rate of 10 $\mathrm{mV} / \mathrm{s}$ was applied. Due to the slower change the current needs about one hour to decline to a minimum of $10 \mu \mathrm{A}$ and rises when a potential of approximately $20 \mathrm{~V}$ is obtained. At the time the potential is equal to $5 \mathrm{~V}$, the current is decreased to about $10 \mu \mathrm{A}$ for a second time.

Fig. 6 demonstrates top and bottom views of the nanotubes obtained at 60V (Fig. 6a) and after applying the different potential ramps to $100 \mathrm{~V}$ (Fig. 6b and c) and 5V (Fig. 6d and e) as described in Fig. 5. No change at the tube tops can be observed since, in all cases, the titanium foils were initially anodized applying equal conditions. However, the bottom of the nanotubes exhibited considerable differences, which are particularly apparent from highmagnification views of the tube bottoms. The differences were quantified using thorough morphological statistics, as shown in Table 2, that provided an overview of the tube diameters, nanotube counts and summarizes the differences verbally. In comparison to the nanotubes obtained under regular anodization, i.e. by keeping the potential constantly at $60 \mathrm{~V}$ (Fig. 6a), larger gaps between the nanotube bottoms were observed when changing the applied potential towards the end of the anodization time in all cases. In addition, different counts of nanotubes on geometrically identical surface areas were revealed. 


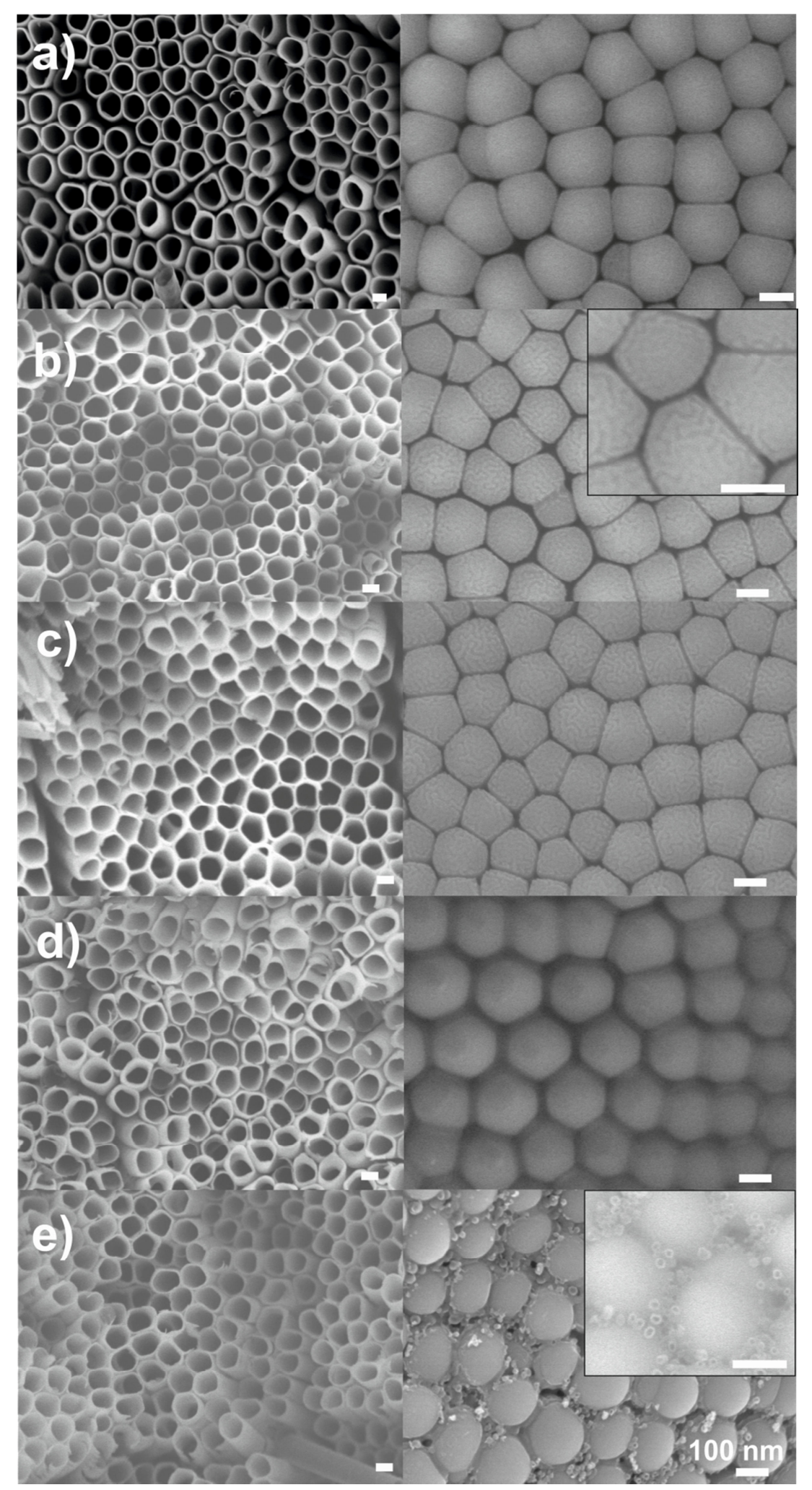

Figure 6. SEM images of tops and bottoms of $\mathrm{TiO}_{2}$ nanotubes anodized 4 hours at $60 \mathrm{~V}$ (a), anodized 4 hours at $60 \mathrm{~V}$ and 1 hour at $100 \mathrm{~V}(\mathrm{~b}, \mathrm{c}), 4$ hours at $60 \mathrm{~V}$ and 1 hour at $5 \mathrm{~V}(\mathrm{~d}, \mathrm{e})$. The potential was changed with $1 \mathrm{~V} / \mathrm{s}$ (b, d) and $10 \mathrm{mV} / \mathrm{s}$ (c, e), respectively. The bar shows $100 \mathrm{~nm}$ in all cases. The inset in Fig. 6b shows the brain structure and the inset in Fig 6e shows the new tubes in detail. 
Firstly the nanotube diameter will be discussed in detail. As shown in Fig. 4, the nanotube diameter increased with the applied potential, if the potential is applied from the very beginning without any further change. However, when the potential was increased to $100 \mathrm{~V}$ after 4 hours at $60 \mathrm{~V}$ (see Fig. $6 \mathrm{~b}$ and $\mathrm{c}$ and Tab. 2) the diameter did not increase to the value obtained after anodization at $100 \mathrm{~V}$ for 4 hours (see Fig. 4). This was due to the fact that the nanotubes were already formed (self-organized) at the lower potential with a certain diameter (corresponding to $60 \mathrm{~V}$ ), and by the time of potential change the nanotube layer was fully developed. Nevertheless, if the potential is increased after the self-organization of the tubes no space between adjacent tubes is left for an enlargement of the nanotube diameter, and the tubes retain the same diameter as for anodization at $60 \mathrm{~V}$.

There were some noticeable differences, at the bottom of the tubes grown at $100 \mathrm{~V}$; a brain structure or nano-crinkles can be observed (Fig. 6b and c). This pattern might be due to comparably increased field-aided dissolution and etching of the $\mathrm{TiO}_{2}$ at the nanotube bottom by fluoride ions [46]. Furthermore, looking at the tube length in detail, when the potential was increased to $100 \mathrm{~V}$ at the end of the anodization time, the resulting nanotubes were significantly longer than those nanotubes fabricated with a constantly applied potential, which have a length of approximately $10 \mu \mathrm{m}$ and an aspect ratio of $\sim 71$. For comparison, tubes with a length and an aspect ratio of $\sim 44 \mu \mathrm{m} / \sim 317$, and $\sim 56 \mu \mathrm{m} / \sim 337$ were observed after an additional 1 hour at $100 \mathrm{~V}$, reached with a sweep rate of $1 \mathrm{~V} / \mathrm{s}$ and $10 \mathrm{mV} / \mathrm{s}$, respectively. This shows that the nanotubes were growing faster at higher potentials, in line with Figure 4, and previous literature [38-42].

By decreasing the applied potential to $5 \mathrm{~V}$ using fast sweeping $(1 \mathrm{~V} / \mathrm{s})$ the growth of the tubes stopped. No new nanotubes were made any longer, or more precisely, the existing nanotubes do not get longer upon these conditions, even when the potential $(5 \mathrm{~V})$ was kept for longer time (e.g. 1 hour). As a consequence of the growth stop of the initial nanotubes, the aspect ratio of the nanotubes in case of a rapid potential reduction to $5 \mathrm{~V}$ was similar to the aspect ratio obtained by applying a constant potential of $60 \mathrm{~V}$, i.e. 71 vs. 90 , respectively. In the case of a slow potential reduction to $5 \mathrm{~V}$ the aspect ratio slightly increased to 123 . This was due to the fact that the tubes kept on growing until the electric field became too low for the nanotube growth. In case of a slow potential reduction a comparatively longer time (approximately 90 minutes more) was needed until the electric field was too small for the tube growth.

Nevertheless, if the potential is reduced slowly $(10 \mathrm{mV} / \mathrm{s})$ large gaps between the tubes are observed at the end of anodization (5 V kept for 1 hour), and numerous new small tubes with 
a diameter of approximately $20 \mathrm{~nm}$, were developed in the cavities between the bottoms of the big tubes (Fig. 6e). The observation of small tubes represents an interesting mechanistic aspect of the tube growth. This phenomenon was not seen when the potential was reduced quickly (1 V/s, as shown in Fig. 6d). The differences might be explained by the current density-time plots. As previously mentioned, if the potential decays fast, the current density becomes comparably small (the smallest from all other densities). The electric field over the oxide layer suddenly becomes too small. As a result, there is no driving force for the tube growth. Even though the current density increased again shortly after $5 \mathrm{~V}$ have been reached, the electric field was not sufficient for the tube growth. Instead, the current goes to some parasitic reactions, such as growth of a thin diffuse oxide layer at the bottoms of the tubes, which is apparent from Fig. 6d. Due to this it was impossible to obtain sharp SEM images of the nanotube bottoms.

On the other hand, in case of a slow decay of the potential, the current density increased when a potential of about $20 \mathrm{~V}$ is reached. At this potential the initially grown nanotubes (at $60 \mathrm{~V}$ ) do not grow any further but, however, small tubes in the gaps between the initial nanotubes can grow. Similar to our observation, Wang et al. found small tubes in the gaps between the initial nanotubes when the applied potential was abruptly changed from $30 \mathrm{~V}$ to $15 \mathrm{~V}$ [47]. Although in this work different conditions were employed, the growth of small nanotubes occurred at a comparable potential and upon similar action.

For both cases (increase to $100 \mathrm{~V}$ from $60 \mathrm{~V}$, decrease from $60 \mathrm{~V}$ to $5 \mathrm{~V}$ ), as a consequence of changes between the size of the gaps, the total number of nanotubes occupying the given surface area is changed. As one can see from Table 2 , the number of nanotubes $/ \mu \mathrm{m}^{2}$ is the highest in case of constantly applied $60 \mathrm{~V}$. Under these conditions the gaps between the nanotube bottoms were small in comparison to the others. The largest gaps, and smallest number of nanotubes $/ \mu \mathrm{m}^{2}$, were received in case of a potential decrease to $5 \mathrm{~V}$.

\begin{tabular}{|l|l|l|l|}
\hline $\begin{array}{l}\text { Applied voltage / } \\
\text { ( }\end{array}$ & $\begin{array}{l}\text { Number of tubes / } \\
\mu m^{2} \text { (Bottom) }\end{array}$ & $\begin{array}{l}\text { Average diameter } \\
\text { of tube bottoms / } \\
\mathrm{nm}\end{array}$ & $\begin{array}{l}\text { Deviation from the } \\
\text { standard 60V } \\
\text { behavior / situation }\end{array}$ \\
\hline 60 & $48 \pm 10.7$ & $161.5 \pm 31.7$ & N.A. \\
\hline $\begin{array}{l}60 \rightarrow 5 \\
(10 \mathrm{mV} / \mathrm{s})\end{array}$ & $39 \pm 4$ & $162.4 \pm 17.9$ & $\begin{array}{l}\text { Comparably large } \\
\text { gaps between } \\
\text { tubes + new small } \\
\text { tubes in gaps }\end{array}$ \\
\hline
\end{tabular}




\begin{tabular}{|l|l|l|l|}
\hline $\begin{array}{l}60 \rightarrow 5 \\
(1 \mathrm{~V} / \mathrm{s})\end{array}$ & $37 \pm 6.6$ & $163.2 \pm 27.5$ & $\begin{array}{l}\text { Comparably large } \\
\text { gaps between } \\
\text { tubes }\end{array}$ \\
\hline $\begin{array}{l}60 \rightarrow 100 \\
(10 \mathrm{mV} / \mathrm{s})\end{array}$ & $41 \pm 1.7$ & $159.1 \pm 23.7$ & $\begin{array}{l}\text { Slightly larger gaps } \\
\text { between tubes }\end{array}$ \\
\hline $\begin{array}{l}60 \rightarrow 100 \\
(1 \mathrm{~V} / \mathrm{s})\end{array}$ & $43.5 \pm 4.3$ & $154.8 \pm 22.6$ & $\begin{array}{l}\text { Slightly larger gaps } \\
\text { between tubes }\end{array}$ \\
\hline
\end{tabular}

Table 2. Evaluation of the amount of nanotubes per $\mu \mathrm{m}^{2}$, bottom diameters and deviations from the standard behaviour.

\subsection{Adhesion of the nanotube layers on the substrates}

When samples shown in Figure 6 were submitted for SEM analyses, noticeable differences were observed in the adhesion of the nanotube layers upon cross-sectioning. In other words, it became obvious that the adhesion of the prepared nanotubes on the substrates changed. This was an interesting feature for further applications of nanotube layers, for instance for an easier preparation of free-standing membranes compared to the state-of-art [28]. Therefore, adhesion tests were carried out.

For adhesion tests the nanotube layers on the substrates were thoroughly removed by $1 \mathrm{~kg}$ weights attached to the nanotubes with a two-component adhesive. The advantage of this adhesive is the capability of quantitative nanotube removal from the substrates, as shown in Fig. 7. In performing these tests, the adhesion between the nanotubes and the titanium substrate was analysed, with fabrication performed under the following conditions; titanium foils were anodized constantly at $60 \mathrm{~V}$, and then the potential was reduced to $5 \mathrm{~V}$ towards the end of the anodization time with $1 \mathrm{~V} / \mathrm{s}$ and $10 \mathrm{mV} / \mathrm{s}$, respectively, and held at $5 \mathrm{~V}$ for 1 hour. The results have shown that the adhesion of nanotubes prepared by a slow sweep to $5 \mathrm{~V}$ is about $6 \%$ lower than nanotubes grown constantly at $60 \mathrm{~V}$, while the nanotubes produced with a fast sweep rate have a slightly higher adhesion ( $1.5 \%$ higher) compared to nanotubes grown constantly at $60 \mathrm{~V}$.

Presumably, differences in the adhesion were due to variations in the contact area between the nanotubes and the substrate. In case of a fast potential sweep towards $5 \mathrm{~V}$ a diffuse oxide layer was developed between the nanotube bottoms and the substrate resulting in a slightly stronger adhesion than for nanotubes produced at a constant potential of $60 \mathrm{~V}$. On the other 
hand, when the potential was swept slowly towards $5 \mathrm{~V}$ the contact to the substrate was made by the new small tubes which partly exceeded the original nanotubes in length (see inset of Fig. 6e). Therefore, the contact area between the nanotubes and the substrate was smaller than in the other cases and, thus, a lower adhesion was received.

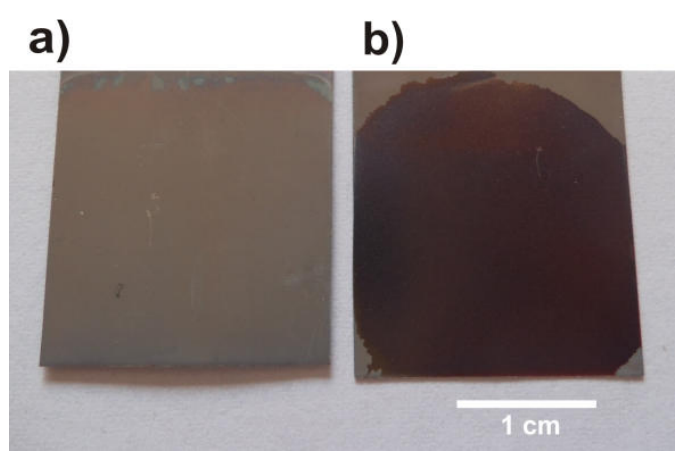

Figure 7. Photographs of the nanotube layer on titanium substrates (a) before and (b) after the quantitative removal of the nanotube layer for adhesion tests. The circular shape seen in Fig. $7 \mathrm{~b}$ stems from the circular target used for nanotube detachment.

Until now, several alternatives are reported to obtain free-standing nanotube membranes, e.g. by dissolution of the substrate in $\mathrm{Br}_{2} / \mathrm{CH}_{3} \mathrm{OH}$, by sonication in an alcohol or by etchants [4850]. These procedures typically involve the use of toxic chemicals. However, since the adhesive is soluble in some organic solvents, e.g. xylene, this adhesion approach has demonstrated a new pathway in the delamination of nanotube layers from the titanium substrate, for facile fabrication of free-standing membranes.

\section{Conclusions}

The results have demonstrated that ethylene glycol based electrolytes perform well for the anodization of titanium, also with repetitive use. However, the older the electrolyte is the weaker it becomes for the nanotube growth due to the loss of fluoride ions. When applying the conditions used in this work, i.e. an applied potential of $60 \mathrm{~V}$ for 6 hours, the aspect ratio decreased strongly from $\sim 210$ in a fresh electrolyte to $\sim 23$ in an electrolyte used for about 50 hours. The optimal electrolyte age for anodizations at $60 \mathrm{~V}$ in the presented electrolyte is in the range from 0 to $\sim 35$ hours after aging.

When the applied potential was swept towards $100 \mathrm{~V}$ at the end of the anodization period, longer nanotubes were obtained, when compared with a constant potential applied during anodization. The nanotube diameter remained the same as for nanotubes grown at $60 \mathrm{~V}$, 
while the nanotube length significantly increased at $100 \mathrm{~V}$. This clearly shows that nanotubes with a higher aspect ratio, but same tube diameter, can be grown under these conditions compared to $60 \mathrm{~V}$ only. However, the bottoms of nanotubes grown at $100 \mathrm{~V}$ showed a brain structure due to an increased attack of the bottoms by fluoride ions. By reducing the applied potential slowly to $5 \mathrm{~V}$ after anodization at $60 \mathrm{~V}$ for 4 hours, the small nanotubes with a diameter of $20 \mathrm{~nm}$ were grown in the gaps between the initial nanotubes.

Adhesion tests revealed lower adhesion of the nanotube layers to the substrates when the potential was reduced slowly to $5 \mathrm{~V}$ than when a constant potential of $60 \mathrm{~V}$ was applied during anodization. However, when the potential was swept rapidly to $5 \mathrm{~V}$ a slightly higher adhesion was received. Furthermore, the use of the adhesive demonstrates a new pathway for the delamination of nanotube layer.

\section{Acknowledgements}

ERC and the Czech Science Foundation are acknowledged for financial support of this work through projects 638857 and 14-20744S, respectively. We thank to Mr. Jan Prikryl for technical support.

\section{References}

[1] M. Assefpour-Dezfuly, C. Vlachos, E. H. Andrews, Oxide morphology and adhesive bonding on titanium surfaces, J. Mater. Sci. 19 (1984) 3626.

[2] V. Zwilling, M. Aucouturier, E. Darque-Ceretti, Anodic oxidation of titanium and TA6V alloy in chromic media. An electrochemical approach, Electrochim. Acta 45 (1999) 921.

[3] J. M. Macak, H. Tsuchiya, A. Ghicov, P. Schmuki, Dye-sensitized anodic $\mathrm{TiO}_{2}$ nanotubes, Electrochem. Commun. 7 (2005) 1133.

[4] K. Zhu, N. R. Neale, A. Miedaner, A. J. Frank, Enhanced Charge-Collection Efficiencies and Light Scattering in Dye-Sensitized Solar Cells Using Oriented $\mathrm{TiO}_{2}$ Nanotubes Arrays, Nano Lett. 7 (2007) 69.

[5] D.-J. Yang, H. Park, S.-J. Cho, H.-G. Kim, W.-Y. Choi, TiO2-nanotube-based dyesensitized solar cells fabricated by an efficient anodic oxidation for high surface area, J. Phys. Chem. Solids 69 (2008) 1272. 
[6] P. Roy, D. Kim, K. Lee, E. Spiecker, P. Schmuki, $\mathrm{TiO}_{2}$ nanotubes and their application in dye-sensitized solar cells, Nanoscale 2 (2010) 45.

[7] J. Liang, G. Zhang, Y. Yang, J. Zhang, Highly ordered hierarchical $\mathrm{TiO}_{2}$ nanotube arrays for flexible fiber-type dye-sensitized solar cells, J. Mater. Chem. A 2 (2014) 19841.

[8] O. K. Varghese, D. Gong, M. Paulose, K. G. Ong, C. A. Grimes, Hydrogen sensing using titania nanotubes, Sens. Actuators, B 93 (2003) 338.

[9] D.-W. Wang, H.-T. Fang, G. Q. Lu, Z. H. Jiang, H.-M. Cheng, Amorphous $\mathrm{TiO}_{2}$ nanotube arrays for low-temperature oxygen sensors, Nanotechnology 19 (2008) 405504.

[10] J. Lee, D. H. Kim, S.-H. Hong, J. Y. Jho, A hydrogen gas sensor employing vertically aligned $\mathrm{TiO}_{2}$ nanotube arrays prepared by template-assisted method, Sens. Actuators, B 160 (2011) 1494.

[11] P. M. Perillo, D.F. Rodríguez, The gas sensing properties at room temperature of $\mathrm{TiO}_{2}$ nanotubes by anodization, Sens. Actuators, B 171-172 (2012) 639.

[12] R. Lü, W. Zhou, K. Shi, Y. Yang, L. Wang, K. Pan, C. Tian, Z. Ren, H. Fu, Alumina decorated $\mathrm{TiO}_{2}$ nanotubes with ordered mesoporous walls as high sensitivity NOx gas sensors at room temperature, Nanoscale 5 (2013) 8569.

[13] M. Kalbacova, J.M. Macak, F. Schmidt-Stein, C.T. Mierke, P. Schmuki, TiO 2 nanotubes: photocatalyst for cancer cell killing, Phys. Stat. Sol. (RRL) 2 (2008) 194.

[14] J. M. Macak, M. Zlamal, J. Krysa, P. Schmuki, Self-Organized $\mathrm{TiO}_{2}$ Nanotube Layers as Highly Efficient Photocatalysts, Small 3 (2007) 300.

[15] Z. Liu, X. Zhang, S. Nishimoto, T. Murakami, A. Fujishima, Efficient Photocatalytic Degradation of Gaseous Acetaldehyde by Highly Ordered $\mathrm{TiO}_{2}$ Nanotube Arrays, Environ. Sci. Technol. 42 (2008) 8547.

[16] J. Park, S. Bauer, K. von der Mark, P. Schmuki, Nanosize and Vitality: $\mathrm{TiO}_{2}$ Nanotube Diameter Directs Cell Fate, Nano Lett. 7 (2007) 1686.

[17] N. K. Shrestha, J. M. Macak, F. Schmidt-Stein, R. Hahn, C. T. Mierke, B. Fabry, P. Schmuki, Magnetically Guided Titania Nanotubes for Site-Selective Photocatalysis and Drug Release, Angew. Chem., Int. Ed. 48 (2009) 969.

[18] K. M. Kummer, E. N. Taylor, N. G. Durmas, K. M. Tarquinio, B. Ercan, T. J. Webster, Effects of different sterilization techniques and varying anodized $\mathrm{TiO}_{2}$ 
nanotube dimensions on bacteria growth, J. Biomed. Mater. Res., Part B 101 (2013) 677.

[19] D. Gong, C. A. Grimes, O. K. Varghese, W. Hua, R. S. Singh, Z. Chen, E. C. Dickey, Titanium oxide nanotube arrays prepared by anodic oxidation, J. Mater. Res. 16 (2001) 3331.

[20] R. Beranek, H. Hildebrand, P. Schmuki, Self-Organized Porous Titanium Oxide Prepared in $\mathrm{H}_{2} \mathrm{SO}_{4}$ / HF Electrolytes, Electrochem. Solid-State Lett. 6 (2003) B12.

[21] J. M. Macak, H. Tsuchiya, P. Schmuki, High-Aspect-Ratio TiO2 Nanotubes by Anodization of Titanium, Angew. Chem. Int. Ed. 44 (2005) 2100.

[22] J. M. Macak, K. Sirotna, P. Schmuki, Self-organized porous titanium oxide prepared in $\mathrm{Na}_{2} \mathrm{SO}_{4} / \mathrm{NaF}$ electrolytes, Electrochim. Acta 50 (2005) 3679.

[23] J. M. Macak, H. Tsuchiya, L. Taveira, S. Aldabergerova, P. Schmuki, Smooth Anodic TiO2 Nanotubes, Angew. Chem. Int. Ed. 44 (2005) 7463.

[24] J. M. Macak, P. Schmuki, Anodic growth of self-organized anodic $\mathrm{TiO}_{2}$ nanotubes in viscous electrolytes, Electrochim. Acta 52 (2006) 1258.

[25] S. P. Albu, A. Ghicov, J. M. Macak, P. Schmuki, $250 \mu \mathrm{m}$ long anodic TiO2 nanotubes with hexagonal self-ordering, Phys. Stat. Sol. (RRL) 1 (2007) R65.

[26] S. P. Albu, D. Kim, P. Schmuki, Growth of Aligned $\mathrm{TiO}_{2}$ Bamboo-Type Nanotubes and Highly Ordered Nanolace, Angew. Chem. Int. Ed. 47 (2008) 1916.

[27] G. Ali, H. J. Kim, J. J. Kim, S. O. Cho, Controlled fabrication of porous doublewalled nanotubes via ultraviolet-assisted anodization, Nanoscale 6 (2014) 3632.

[28] K. Lee, A. Mazare, P. Schmuki, One-Dimensional Titanium Dioxide Nanomaterials: Nanotubes, Chem. Rev. 114 (2014) 938.

[29] F. Mohammadpour, F. Behzad, M. Moradi, Fast anodically growth of long, small diameter $\mathrm{TiO}_{2}$ nanotubes by electropolishing of $\mathrm{Ti}$ foils in an ethanol-containing solution, Mater. Lett. 150 (2015) 81.

[30] J. M. Macak, S. Albu, P. Schmuki, Towards ideal hexagonal self-ordering of $\mathrm{TiO}_{2}$ nanotubes, Phys. Stat. Sol. (RRL) 1 (2007) 181.

[31] G. Zhang, H. Huang, Y. Zhang, H. L.W. Chan, L. Zhou, Highly ordered nanoporous $\mathrm{TiO}_{2}$ and its photocatalytic properties, Electrochem. Commun. 9 (2007) 2854.

[32] S. Li, G. Zhang, D. Guo, L. Yu, W. Zhang, Anodization Fabrication of Highly Ordered $\mathrm{TiO}_{2}$ Nanotubes, J. Phys. Chem. C 113 (2009) 12759. 
[33] J. M. Macak, S. Albu, D. H. Kim, I. Paramasivam, S. Aldabergerova, P. Schmuki, Multilayer $\mathrm{TiO}_{2}-$ Nanotube Formation by Two-Step Anodization, Electrochem. Solid-State Lett. 10 (2007) K28.

[34] S. K. Mohapatra, M. Misra, V. K. Mahajan, K. S. Raja, Synthesis of Y-branched $\mathrm{TiO}_{2}$ nanotubes, Mater. Lett. 62 (2008) 1772.

[35] B. Chen, K. Lu, Hierarchically Branched Titania Nanotubes with Tailored Diameters and Branch Numbers, Langmuir 28 (2012) 2937.

[36] P. Roy, S. Berger, P. Schmuki, $\mathrm{TiO}_{2}$ Nanotubes: Synthesis and Applications, Angew. Chem. Int. Ed. 50 (2011) 2904.

[37] A.Ghicov, H. Tsuchiya, J. M. Macak, P. Schmuki, Titanium oxide nanotubes prepared in phosphate electrolytes, Electrochem. Commun. 7 (2005) 505.

[38] S. Bauer, S. Kleber, P.Schmuki, $\mathrm{TiO}_{2}$ nanotubes: Tailoring the geometry in $\mathrm{H}_{3} \mathrm{PO}_{4} / \mathrm{HF}$ electrolytes, Electrochem. Commun. 8 (2006) 1321.

[39] J. M. Macak, H. Hildebrand, U. Marten-Jahns, P. Schmuki, Mechanistic aspects and growth of large diameter self-organized $\mathrm{TiO}_{2}$ nanotubes, J. Electroanal. Chem. $621(2008) 254$.

[40] G. Loget, S. So, R. Hahn, P. Schmuki, Bipolar anodization enables the fabrication of controlled arrays of $\mathrm{TiO}_{2}$ nanotube gradients, J. Mater. Chem. A 2 (2014) 17740.

[41] K. Kant, D. Losic, Self-Ordering Electrochemical Synthesis of $\mathrm{TiO}_{2}$ Nanotube Arrays: Controlling the Nanotube Geometry and the Growth Rate, J. Nanosci. 10 (2011) 55 .

[42] L. Yin, S. Ji, G. Liu, G. Xu, C. Ye, Understanding the growth behavior of titania nanotubes, Electrochem. Commun. 13 (2011) 454.

[43] S. P. Albu, P. Schmuki, Influence of anodization parameters on the expansion factor of $\mathrm{TiO}_{2}$ Nanotubes, Electrochim. Acta 91 (2013) 90.

[44] K. Yasuda, J. M. Macak, S. Berger, A. Ghicov, P. Schmuki, Mechanistic Aspects of the Self-Organization Process for Oxide Nanotube Formation on Valve Metals, J. Electrochem. Soc. 154 (2007) C472.

[45] J.M. Macak, H. Tsuchiya, A. Ghicov, K. Yasuda, R. Hahn, S. Bauer, P. Schmuki, $\mathrm{TiO}_{2}$ nanotubes: Self-organized electrochemical formation, properties and applications, Curr. Opin. Solid State Mater. Sci.11 (2007) 3. 
[46] J. Ni, K. No, C. J. Frandsen, S. D. Kong, G. He, T. Tang, S. Jin, Preparation of near micrometer-sized $\mathrm{TiO}_{2}$ nanotube arrays by high voltage anodization, Mater. Sci. Eng. C 33 (2013) 259.

[47] X. Wang, L. Sun, S. Zhang, D. Zhao, On seeding of the second layer in growth of double-layered $\mathrm{TiO}_{2}$ nanotube arrays, Electrochim. Acta 107 (2013) 200.

[48] S. P. Albu, A. Ghicov, J. M. Macak, R. Hahn, P. Schmuki, Self-organized, freestanding $\mathrm{TiO}_{2}$ nanotube membrane for flow-through photocatalytic applications, Nano Lett. 7 (2007) 1286.

[49] Q. W. Chen, D. S. Xu, Z. Y. Wu, Z. F. Liu, Free-standing $\mathrm{TiO}_{2}$ nanotube arrays made by anodic oxidation and ultrasonic splitting, Nanotechnology 19 (2008) 365708 .

[50] C. J. Lin, W. Y. Lu, Y. T. Lu, S. H. Chien, Fabrication of open-ended high aspectratio anodic $\mathrm{TiO}_{2}$ nanotube films for photocatalytic and photoelectrocatalytic applications, Chem. Commun. 45 (2008) 6031.

(C) 2015. This manuscript version is made available under the CC-BY-NC-ND 4.0 license http://creativecommons.org/licenses/by-nc-nd/4.0 